\title{
CARRANCAS E CRIANÇAS NOVAS FORMAS DE APROPRIAÇÃO DA ARTE POPULAR BRASILEIRA
}

\author{
Maria Vittoria de Carvalho Pardal (UFRJ) \\ Adriana Russi (UniRio) \\ Nayara Alves Macedo (UFF) \\ Ana Luiza Cordeiro de M. Barbosa (UFF)
}

Este trabalho apresenta uma possibilidade de aproximar crianças da arte popular brasileira, através de abordagem lúdica, utilizando artefatos como as carrancas do Rio São Francisco, foco da experiência aqui relatada, que integra programa de extensão da Universidade Federal Fluminense cujo objetivo é criar formas inovadoras de trabalhar a educação patrimonial.

\section{EDUCAÇÃO, PATRIMÔNIO CULTURAL, COLEÇÃO.}




\section{INTRODUÇÃO}

A Universidade Federal Fluminense vem, desde 2008, desenvolvendo programa de extensão que envolve docentes e discentes da Faculdade de Educação da Universidade Federal Fluminense - Feuff, do Laboratório de Educação Patrimonial - Laboep, coordenado pela professora Lygia Segalla, e do Curso de Produ-

1. A coleção a que se refere o artigo foi constituída por Paulo Pardal e sua mulher, Lully de Carvalho. É composta por mobílias, instrumentos, carrancas, objetos de arte e outros tantos e fica abrigada num casarão colonial em Barra de São João, distrito de Casimiro de Abreu, RJ. ção Cultural do Polo Universitário de Rio das Ostras - Puro, e tem como objetivo viabilizar o uso social da coleção de arte popular e do casarão colonial localizado em Barra de São João que pertenceram a Paulo Pardal e Lully de Carvalho, ${ }^{1}$ através de criação de abordagem inovadora na área da educação patrimonial.

Intitulado Casa das Mil Casas, o programa busca expressar a multiplicidade de recortes e abordagens que poderão ser trabalhados a partir do acervo, tanto no que se refere às possíveis temáticas sugeridas pelos objetos e às fundamentações teóricas que lhes confiram inteligibilidade quanto às diferentes linguagens artísticas utilizadas. Dessa forma, a casa, embora una,

torna-se múltipla, pois se transforma de acordo com os diferentes atores sociais e suas diversas apropriações.

A proposta da Casa das Mil Casas, contudo, não se restringe ao casarão sediado em Barra de São João. Ao contrário, abre-se para a possibilidade de realizar atividades em diferentes espaços físicos, numa perspectiva de desterritorialização das ações, como se verá adiante, no exemplo da oficina Carrancas e o medo, desenvolvida com as crianças da creche da Universidade Federal Fluminense.

Atende, assim, a toda a riqueza latente na concepção de um verdadeiro programa de extensão universitário, posto que é capaz de abrigar projetos de diferentes áreas do conhecimento.

Essa proposta visa sobretudo a uma "experiência de qualidade", inspirada na concepção de Walter Benjamin e de John Dewey, a partir do contato do visitante/participante com os objetos da coleção.

Walter Benjamin (1985, p. 119) já tratava do afastamento do homem de suas experiências; ou melhor, ele descreveu a pobreza de experiências a que o homem moderno estava sujeito. Em sua análise crítica do desenvolvimento da técnica e sua sobreposição ao homem, este estaria "sufocado" com o tipo de vida a que a modernidade o conformou e por fim, desejaria libertar-se de toda experiência, pois:

aos olhos das pessoas, fatigadas com as complicações infinitas da vida diária e que veem o objetivo da vida apenas como o mais remoto ponto de fuga numa interminável perspectiva de meios, surge uma existência que se basta a si mesma, em cada episódio, do modo mais simples e mais cômodo.

Essa subtração da experiência, essa pobreza de experiência da própria existência humana, conduz Walter Benjamin a um questionamento do valor do patrimônio cul- 
tural já que a experiência não mais a ele o vincula. Foi com vistas a desenvolver proposta que conduza o visitante/participante a uma experiência de qualidade centrada não num mero passar de olhos, numa visita rápida ao casarão ou a sua coleção, mas num momento de encontro, de memória e construção de subjetividade que o programa de extensão da UFF foi concebido.

Os objetos, porém, embora portadores de inúmeras camadas de histórias e apropriações humanas, usos e sentidos, pouco nos dizem, sobretudo se estivermos espaçotemporalmente distanciados de suas origens. Assim, Chagas e Santos (2002, p. 208) questionam a "capacidade que temos de compreender as relações sociais que constituíram os objetos" expostos num museu, por exemplo. Objetos, artefatos, mobiliários, etc. dispostos em exposições representam e expressam processos históricos; são como testemunhas silenciosas, e precisamos "desenterrar" os discursos que neles subjazem. Segundo esses autores,

Parece razoável admitir que o que faz os objetos saírem do seu silêncio é o interesse do público e que, ainda assim, uma exposição de objetos é mais do que uma exposição de objetos, é também uma mostra de saberes, fazeres, sentimentos, valores, interesse etc. (p.217).

Em sua antropologia dos objetos, José Reginaldo Gonçalves $(2007$, p. 8) se refere a sua "função social", cuja potência precisa ser explicitada, decodificada - especialmente quando fora de seus contextos originais:

Seja no contexto de seus usos sociais e econômicos cotidianos, seja em seus usos rituais, seja quando reclassificados como itens de coleções, peças de acervos museológicos ou patrimônios culturais, os objetos materiais existem sempre, necessariamente, como partes integrantes de sistemas classificatórios. Esta condição lhes assegura o poder não só de tornar visíveis e estabilizar determinadas categorias socioculturais, demarcando fronteiras entre estas, como também o poder, não menos importante, de construir sensivelmente formas específicas de subjetividade individual e coletiva.

Em outras palavras, mais do que meras invenções dos homens, os objetos, aos quais atribuímos funções e sentidos, estão também a nos "inventar" enquanto seres humanos, enquanto membros de uma aldeia ou de uma comunidade ou cidade.

A partir desses conceitos, o programa de extensão pretende aproximar visitante/participante dos objetos que constituem a coleção de Paulo Pardal e Lully de Carvalho para que esses bens culturais sejam ressignificados e, assim, permitam a compreensão e reelaboração de seus sentidos.

Para tanto, temos nos debruçado na elaboração de proposta metodológica na área de educação e patrimônio com abordagem sociointeracionista. Sob essa perspectiva de desenvolvimento humano, embasada em Vygotsky (1984), entendemos que o processo de desenvolvimento se consolidará na relação de troca com o outro, através da interação e da mediação simbólica. Segundo esse teórico, o sujeito é por excelência interativo, pois cria e amplia sua forma de agir no mundo através das relações interpessoais e do contato com o meio, que é entendido como social e cultural. As características intrapsí- 
quicas do sujeito são formadas a partir das interações interpessoais, sendo, portanto, impregnadas do coletivo.

Nessa perspectiva, os objetos são considerados mediadores da atividade humana que, dialeticamente, criados pelo homem, também participam da produção da subjetividade humana. Ao mediar as ações humanas com outros homens e com a natureza, produzem, simultaneamente, uma forma específica de existir no mundo, de viver a existência humana, de inventar a vida. Diferentes povos e em diferentes momentos históricos criaram e utilizaram objetos específicos que, por sua vez, modelaram as formas de esses povos viverem as relações sociais, os afetos, a cognição.

Debruçar-se sobre os objetos da coleção permite um mergulho no tempo, um deslocamento espaçotemporal que possibilia repensar nossas relações sociais cotidianas atuais. Revisitar os utensílios domésticos da coleção que data do início do século XIX nos remete, por exemplo, às transformações da condição feminina e de que forma a técnica é capaz de modificar o cotidiano das mulheres e as relações de gênero.

Da mesma forma, constatar que as populações ribeirinhas do médio São Francisco lidavam com seus medos do caboclo-d'água, da mãe-d'água e do minhocão criando escultura de extrema beleza plástica - a carranca -ajuda-nos a refletir sobre os recursos que o homem moderno utiliza para domesticar seus temores.

Com essa finalidade idealizamos oficinas que podem ser realizadas tanto no casarão (em seu galpão e jardins) quanto em outros espaços educativos ou museais. As oficinas, com duração variável de três a quatro horas, têm como princípio estabelecer uma relação reflexiva do participante com os objetos.

O objetivo principal é, utilizando as peças já catalogadas do acervo, atuar na promoção da construção da subjetividade através da arte, do patrimônio e da relação com o outro, em situações que estabeleçam sentidos e com o recurso de diversas linguagens escrita, oral, musical, teatral, corporal, plástica, literária, entre outras.

A arte nesse programa é compreendida como forma de manifestação da cultura humana. Influenciadas por Clifford Geertz (1997), tomamos a arte como um sistema mais bem compreendido através da apreensão da cultura a que pertence. Nessa abordagem, um objeto artístico não é um dado natural, mas socialmente construído e compartilhado por códigos estabelecidos entre os membros de cada sociedade humana em que forma $\mathrm{e}$ conteúdo compõem uma unidade. Por fazerem parte do curso normal da vida social, não cabe entender esses objetos como "meros encadeamentos de formas".

Assim, na perspectiva de Geertz, estudar a arte é explorar uma sensibilidade essencialmente coletiva, cujas bases são a própria vida social. A apreciação da arte (dos objetos, no caso do programa de extensão), portanto, inclui habilidades discriminatórias que tanto observador quanto criador têm através da experiência de vida.

A intenção desse programa, reiteramos, é provocar uma experiência de qualidade, o que pode ocorrer através da percepção. Para tanto, empregamos o conceito de 
Dewey (1980) de "ter uma experiência", bem como sua compreensão sobre a percepção com vistas a suplantar a pobreza da experiência humana criticada por Benjamin (1985).

Dewey (1980, p. 89) afirma que a experiência ocorre continuamente, pois “(...) a interação da criatura viva com as condições que a rodeiam está implicada no próprio processo da vida". Entretanto, apesar de as coisas serem experimentadas não se configuram em "uma experiência", pois acontecem em substituição umas às outras. "Há experiência, mas tão lassa e digressiva que não é uma experiência" (p.93).

Procuraremos, com o programa, dar oportunidade ao visitante/participante de "ter uma experiência”, o que, segundo o autor, se dá quando o “(...) material experienciado segue seu curso até sua realização. Então, e só então, ela é integrada e delimitada, dentro da corrente geral da experiência, de outras experiências". Nela a situação é tão íntegra, que seu fim é realização e não cessação. Por ser um todo, a experiência “(...) traz consigo sua própria qualidade individualizadora e sua autossuficiência. É uma experiência" (p. 89).

Assim, desejamos que o visitante/participante tenha uma experiência através da percepção dos objetos. Empregamos a noção de percepção de Dewey (1980, p. 102), que difere do simples reconhecimento que recai em esteriótipos, esquemas previamente formados (percepção interrompida antes que essa se desenvolva livremente). A percepção, por outro lado, não é passiva. Permite estudar e "absorver", é atividade reconstrutora em que a consciência torna-se forte e vívida; é um ato ativo, assim descrito:

Este ato de ver implica a cooperação de todos os elementos motores, ainda quando permaneçam implícitos e não se exteriorizem, assim, como a cooperação de todas as ideias acumuladas que possam servir para completar o novo quadro em formação.

E mais:

um ato de percepção processa-se por ondas que se estendem serialmente através de todo o organismo. Não há na percepção, por conseguinte, tal coisa como o ver ou o ouvir e mais a emoção. $\mathrm{O}$ objeto ou cenário percebidos ficam completamente penetrados emocionalmente (p. 103).

Essa concepção de Dewey sobre a percepção está na base das oficinas propostas no programa de extensão.

A partir do trabalho já desenvolvido com o arrolamento dos objetos em coleções e temáticas, estão sendo elaboradas inicialmente cinco oficinas: O uso social dos objetos, trabalho doméstico e transformação do feminino; Arte popular e sexualidade: o erotismo mágico; Carrancas e o medo; Quanto tempo dura o tempo ao longo do tempo; Poder e dominação: as diferentes formas de subjugar o outro ao longo da história.

Partindo do pressuposto de que arte é trabalho humano, no sentido marxista da palavra, não queremos que cada oficina se configure por caminhos reducionistas do mero reconhecimento. Pretendemos que o visitante/participante compreenda historicamente as obras selecionadas e desenvolva sua sensibilidade, criatividade e imaginação, 
2. A creche é a Unidade de Educação Infantil da UFF e atende a 60 crianças de um ano e meio a seis anos, em horário integral, filhos de professores, funcionários e alunos da universidade. Nela são realizados projetos de pesquisa e extensão que envolvem cerca de 60 alunos de diferentes cursos de graduação e pósgraduação. sempre considerando que cada pessoa manifesta suas percepções, emoções e ideias de maneiras diferentes.

Sugerimos que cada oficina tenha um portfólio para catalogar materiais, recursos e estratégias a serem utilizados. Concebemos, assim, cada oficina de forma flexível, ou seja; podemos realizá-las com diferentes públicos (crianças pequenas, adolescentes, estudantes do ensino fundamental, universitários, moradores de Barra de São João, empresários e trabalhadores locais, etc.).

Uma versão da oficina Carrancas e o medo, realizada em 2010 com as crianças de quatro e cinco anos da creche da UFF, ${ }^{2}$ é objeto de estudo de uma monografia de graduação do Curso de Pedagogia e será descrita a seguir.

\section{MÃES-D’ÁGUA, CABOCLOS-D’ÁGUA, MINHOCÕES, CARRANCAS E CRIANÇAS: BRINCANDO COM A ARTE POPULAR BRASILEIRA}

Foi no Rio São Francisco que as primeiras carrancas surgiram, no século XIX. O dicionário Novo Aurélio registra entre os significados de carranca "semblante sombrio; figura de madeira, em geral disforme, que orna a proa de certas embarcações". Segundo um dos maiores escultores de carranca, Francisco Guarany, em seu lugar de origem essas peças eram conhecidas como "figuras de barca" e também chamadas, em Juazeiro, de "leão de barca ou cara de pau".

Carrancas são esculturas talhadas em madeira e colocadas na proa dos barcos. Imagens assustadoras, representam figuras que misturam homens e animais. Pardal (2006), ao discutir o motivo desse zooantropomorfismo das carrancas, encontrou justificativa na dificuldade dos artesãos em reproduzir tecnicamente a figura humana ou de algum animal. Tal dificuldade ainda refletia o fato de que tais cabeças eram esculpidas em pedaços de tronco, o que levava os artesãos a criar a partir das características da própria matéria-prima.

Pardal (2006) trata ainda da história dessas figuras, tão usadas em tempos remotos por diferentes povos: segundo o autor, figuras de proa nas embarcações entre os povos ocidentais apareceram desde a Antiguidade, mas tiveram sua origem no Egito, assemelhando-se à figura de uma caveira de touro. Nesse período também era comum verificar em outros continentes a pintura de olhos nas proas do barco, ressaltando a ideia de a embarcação possuir vida. A partir da Idade Média, as peças constitutivas das figuras passaram a ser móveis, representando animais fantásticos como o dragão, a serpente e o cavalo. Serviam para causar medo e espanto no inimigo. A partir do século XVI as esculturas assumiram a finalidade decorativa e, às vezes, tinham o intuito de representar personalidades. Só no Rio São Francisco, entretanto, encontramos, em tempos modernos, esculturas nas proas das embarcações populares de modo generalizado. 
Devemos agradecer ao isolamento em que viviam os habitantes do médio São Francisco o fato de terem criado um tipo de figura de proa inédito em todo mundo: peças de olhos esbugalhados, misto de homem, com suas sobrancelhas arqueadas, e de animal, com sua expressão feroz e sua cabeleira tipo juba leonina (PARDAL, 1979, p. 6).

Muitos tripulantes das barcas do Rio São Francisco forneceram interpretações sobre o aspecto das esculturas que ornamentavam as embarcações. Na opinião de muitos deles, a aparência assustadora das carrancas servia para os barqueiros como amuleto, proteção contra os espíritos das águas do rio. Francisco Guarany relata que as carrancas protegiam os navegantes dos animais do rio, como peixes gigantes e jacarés. Apesar das superstições que assombravam as mentalidades dos tripulantes das barcas do São Francisco, o uso inicial das carrancas decorreu da necessidade de indicar propriedade nos barcos, servindo como marca de registro dos barqueiros (PARDAL, 2006).

Nem sempre, porém, as carrancas foram consideradas arte - só após longo processo todos se curvaram diante de sua inigualável originalidade e expressividade.

As carrancas do São Francisco são uma manifestação artística coletiva, com caracteres comuns, respeitadas as individualidades de cada artista, como não se encontra em nenhum outro local ou época. Fruto da criação de uma cultura e de uma região isolada do resto do país e do mundo, cujos artistas populares, a partir da ideia de esculpir uma figura de proa, criaram soluções plásticas próprias, de elevado conteúdo artístico e emocional, que provocam um verdadeiro impacto. Possivelmente até negativo, em alguns, mas esta é uma das características de uma verdadeira obra de arte: criar o impacto. Pode haver quem não aprecie as carrancas, mas jamais quem a elas fique indiferente (PARDAL, 1979, p. 22).

\section{MÃOS NA MASSA: OFICINA NA CRECHE DA UFF}

Vencidas as leituras e os estudos para a preparação do que ocorreria na prática a oficina -, já era hora de colocar a mão na massa e sistematizar toda a base teórica em atitudes e propostas necessárias para a intervenção junto às crianças.

Escolhemos para a oficina o grupo $\mathrm{G} 3$, crianças com quatro e cinco anos. Identificado o perfil do grupo, atentamos para a necessidade de trabalhar com material concreto. Nessa faixa etária é imperioso que as crianças tenham oportunidade de vivenciar ações em que seu pensamento esteja ligado ao concreto, já que sua forma de pensar se caracteriza por centrar-se no que é real. Desenvolvemos as atividades, portanto, com base nessas ideias e nesses conceitos.

Tendo em vista o eixo central de trabalhar o patrimônio artístico 'escultura', estabelecemos uma rotina que teve como objetivo situar as esculturas em diferentes momentos históricos, desde a pré-história até a modernidade, incluindo a arte popular brasileira.

A oficina foi dividida em cinco momentos: Tá na roda: o que é escultura?; Varal das obras de arte; Carranca e o medo; Sessão carranca; Dinâmicas. 
Vale salientar que a rotina não foi rígida e inflexivelmente imposta. Durante o decorrer da oficina, muitas vezes as próprias crianças propuseram diferentes encaminhamentos.

\section{PRIMEIRO MOMENTO: TÁ NA RODA: O QUE É ESCULTURA?}

Nos reunimos, então, para discutir nossa proposta de trabalho com o grupo. Todos estavam sentados na rodinha, inquietos para saber o que estaria por vir.

A rodinha é uma das atividades mais conhecidas e utilizadas pelos profissionais que atuam na educação infantil. É compreendida como espaço aberto ao diálogo, em que as crianças são inseridas desde o início como partícipes do planejamento das atividades. Esse momento foi fundamental para o andamento da oficina, posto que utilizado com o intuito de resgatar as experiências e percepções das crianças diante do tema, ramificando redes para a construção de novos saberes.

Importante salientar que na política de ensino/aprendizagem da creche as crianças são sujeitos ativos e participantes, e por isso consideramos fundamental incluir neste artigo alguns trechos de suas falas durante as oficinas realizadas na creche em 2010. Iniciamos, então, nossa conversa sobre arte.

Nayara - O que vocês acham que é escultura? / Criança 1 - É algo que a gente expõe no museu. / Criança 2 - Uma coisa que o homem pode fazer. / Criança 3 - É uma estátua! / Criança 4-A gente modela com massinha e faz uma coisa, aí vira escultura.

A conversa com as crianças, dirigida pela discente do curso de pedagogia Nayara Alves Macedo respeitou as intervenções das crianças, problematizando e explorando as questões que surgiam.

Durante o desenvolvimento das atividades evidenciou-se o modo como se dava o processo de fruição das crianças - a partir de sua curiosidade apaixonada, conversamos sobre os materiais utilizados na confecção de esculturas para trabalhar o tema. Foram apresentados fragmentos de madeira, mármore, gesso e argila. As crianças puderam tocar e sentir as características de cada um - temperatura, textura, peso, o que as fez perceberem as diferenças. Das expressões das crianças, destacamos:

Criança 1 - 0 mármore é frio. / Criança 2 - Esse aqui [gesso] dá para pintar! / Criança 3 - A madeira não é lisinha igual ao mármore. / Criança 4 - O mármore é mais pesado. / Criança 5 - Olha, é argila! Dá para furar como o dedo. / Criança 6 - Não! É para modelar!

\section{SEGUNDO MOMENTO: VARAL DAS OBRAS DE ARTE}

A partir desse momento inicial, percebemos a necessidade de visualizar esculturas e lhes apresentamos imagens de algumas consagradas na história da arte ocidental.

Para que a observação fosse ainda mais aguçada, foram lançadas questões durante a visualização de cada uma das imagens. A iniciativa visava evidenciar semelhanças e diferenças, além de permitir a livre opinião das crianças, que estabeleceram algumas relações, mediadas pela intervenção da discente de pedagogia. 
Depois da análise, explorando os significados das esculturas, as crianças trouxeram importantes observações. A maioria das imagens parecia familiar ao grupo, e o contato estabelecido com as imagens apenas reforçou experiências estéticas anteriores. Entre as imagens analisadas havia uma representação de Apolo, uma de Vênus, e uma escultura de Mestre Vitalino.

Como já mencionado, os objetos, e nesse sentido também a arte, desvelam um contexto sociocultural que lhes é subjacente. Explicamos, então, àquelas crianças de tão pouca idade que cada uma das esculturas havia sido confeccionada por um artista diferente num dado momento histórico.

Para isso fizemos um "varal de imagens de esculturas". A intenção era dar a ideia de linha do tempo, discutindo as contradições e especificidades de cada imagem e a relação entre elas.

As características de cada uma delas foi sublinhada - a representação do corpo humano nu, as formas realistas dos músculos e tronco expostos nas esculturas do classicismo e do Renascimento; dialogamos sobre a arte popular de Mestre Vitalino e seu contexto histórico. Tentamos, juntos, desvendar o que cada imagem queria expressar. Brincamos com a possibilidade de imitar a imagem, numa escultura viva.

Só então é que apresentamos a imagem da carranca que suscitou grande espanto entre as crianças, como fica evidente nesta mediação da aluna de pedagogia:

Nayara - Vocês sabem o que é isso? É uma carranca! Parece com o quê? / Criança 1 - Um cavalo! / Criança 2 - Vampiro! / Criança 3 - Homem-cavalo. / Nayara - Vamos dizer que é uma mistura de homem e animal, com traços de vampiro. / Criança $4-\mathrm{Ai}$, dá medo!

\section{TERCEIRO MOMENTO: A CARRANCA E O MEDO}

No primeiro contato com as carrancas, as crianças demonstraram certo receio e até medo. Para esclarecer o tipo de escultura de que se tratava, localizamos no tempo e no espaço essa produção artística. Abordamos a história dos navegantes do Rio São Francisco e dos barqueiros que colocavam a carranca na proa do barco para afugentar os maus espíritos. Como as crianças ainda demonstravam certo temor, aproveitamos esse clima para um exercício de imaginação: navegamos pelo Rio São Francisco! Mais uma vez, a atividade mediada pela aluna da pedagogia despertou entusiasmo nas crianças:

Nayara - $\mathrm{O}$ que vocês acham de a gente imaginar que estamos navegando no Rio São Francisco com a nossa carranca na proa? / Criança 1 - Legal! Eu quero ser a carranca! / Criança 2 - Eu, os espíritos! / Criança 3 - Sou o barco!

Utilizando materiais como barbante e papel celofane azul, foi realizada com as crianças uma dramatização do momento em que os espíritos encontram a carranca e, ao sentirem medo do objeto, voltam para o fundo do mar sem fazer nenhum mal aos navegantes do rio. 
Apesar desse momento de participação e de grande brincadeira, era necessário frisar a proteção que a carranca oferecia aos barqueiros, já que o amedrontamento que a peça causava ficou mais latente. Outras questões mereciam ser retomadas para garantirmos o sucesso da oficina.

\section{QUARTO MOMENTO: SESSÃO DE VÍDEO SOBRE CARRANCAS}

Sabendo do importante papel da mídia televisiva na vida contemporânea, selecionamos uma reportagem que tratava especificamente das car-

3. Trata-se de uma reportagem durante o programa de Ana Maria Braga, na Rede Globo. rancas do Rio São Francisco para apresentar ao grupo. ${ }^{3}$

Percebemos que durante a reportagem, a participação das crianças foi intensa; mostraram-se entusiasmadas e interessadas nas informações sobre o modo de confecção de uma carranca. Todas ouviam atentamente os depoimentos dos barqueiros e as histórias dos maiores escultores de carrancas: Francisco Guarany e Ana das Carrancas.

Após a exibição da reportagem, apresentamos um mapa do Brasil, para localizar com eles a região do Rio São Francisco, mais especificamente seu trecho médio, de Pirapora, MG até Remanso, BA. Dialogamos sobre as imagens vistas na reportagem, extrapolando a paisagem audiovisual para "navegar na imaginação".

Quando discutimos sobre as peculiaridades da carranca, o grupo ressaltou novamente o espanto expresso nesse tipo de artefato. $E$ foi nesse momento que pudemos inserir a questão das práticas e crenças de proteção de caráter sobrenatural, o que constituiu oportunidade importante para as crianças entenderem o teor protetor da carranca, como observamos em algumas destas frases:

Nayara - Na minha casa, minha mãe acredita que Deus a protege de todo o mal. Quem protege vocês? / Criança 1 - Minha mãe... meu pai... / Criança 2 Deus! / Nayara - Assim como acreditamos que nossa família e Deus nos protegem, os barqueiros do São Francisco acreditavam que as carrancas colocadas na proa dos barcos serviam para protegê-los, tal como um amuleto! A carranca não causava medo nos navegantes. Os espíritos, sim, é que morriam de medo da escultura! / Criança 3 - Nayara, eu também não tenho medo de carranca! / Criança 4 - Nem eu!

\section{QUINTO MOMENTO: DINÂMICAS E UM ATÉ BREVE}

Como última atividade da oficina na creche, foi realizada uma brincadeira em que as crianças utilizaram o próprio corpo para produzir esculturas. E dessa maneira, incentivadas pela mediação da aluna Nayara, de fato passaram para a etapa do fazer artístico.

Nayara - Vamos brincar de escultores? / Criança 1 - Legal! / Criança 2 - Eu quero. / Criança 3 - Como é? / Nayara - Todo escultor tem sua obra-prima, seu material. Lembram da argila, madeira, mármore e gesso que vimos?! Que tal convidarmos um amigo para ser a nossa obra-prima, para tentarmos criar uma escultura? / Criança 4-Eu! 
Uma criança correu e se posicionou no centro do grupo, dando liberdade aos colegas para criar com seu corpo a escultura coletiva.

Em seguida, a dinâmica foi realizada em duplas, que se espalharam por toda a sala em diversas posições: sentadas, deitadas, de pé. Com essa experiência as crianças perceberam a tridimensionalidade da escultura, a importância do tato para sua confecção.

Para finalizar a oficina as crianças fizeram uma rodinha com a intenção de avaliá-la. O grupo manisfestou satisfação com as atividades realizadas e demonstrou interesse pelas carrancas do São Francisco. Na sequência, a aluna Nayara apresentou a proposta de visitar o Museu do Ingá (Niterói, RJ) com as crianças para verem a exposição A quatro mãos, em que teriam oportunidade de conhecer outras carrancas.

\section{VISITANDO O MUSEU: RELATO}

Macedo (2008), ao tratar da etimologia da palavra museu, informa que ela deriva do grego mouséion, que significa templo das musas, especialmente de Mnemosine, deusa da memória. De sacro e privado, o museu passou a laico e público. Só na França pósRevolução Francesa é que esse tipo de instituição foi entendido como "gabinete de trabalho, lugar consagrado aos estudos científicos literários e artísticos de antiquários e amadores" (p. 92), acepção a partir da qual formou-se o conceito de museu adotado pelo International Council of Museums - Icom, da Unesco). Quanto à abrangência da instituição museal, o autor observa:

Atualmente, o museu é uma instituição permanente, sem fins lucrativos, que adquire, preserva, documenta, pesquisa e comunica para educação e lazer e, permanentemente, busca a conservação e apresentação de seu acervo e coleções representativos de um contexto histórico e temporal de uma comunidade (MACEDo, 2008, p. 92).

É também no museu que a prática da educação patrimonial vem-se tornando cada vez mais comum e familiar. Diversas dessas instituições oferecem atividades educativas voltadas para o público infantil, desenvolvidas por profissionais diretamente engajados com o campo educativo e relacionadas às exposições.

O Museu de História e Artes do Estado Rio de Janeiro mais conhecido popularmente como Museu do Ingá formou-se pela união dos Museus Histórico do Estado do Rio de Janeiro e de Artes e Tradições Populares, funcionando no Palácio Nilo Peçanha, também chamado de Palácio do Ingá. É vinculado à Fundação Estadual Artes do Rio Janeiro - Funarj.

Na década de 1970, Paulo Pardal doou ao Museu de Artes e Tradições Populares três carrancas e uma escultura em barro de Ana das Carrancas que integram atualmente seu acervo. De acordo com pesquisas realizada no site do Museu do Ingá, "a instituição possui aproximadamente 4.800 peças entre mobiliário, porcelanas, acessórios de indumentária, documentos, cristais, esculturas, fotografias, numismática e pinturas", organi- 
zadas em cinco coleções assim nomeadas: Arte Popular, Palácio do Ingá, Lucílio de Albuquerque, Banerj e Amaral Peixoto.

Nossa visita ocorreu durante a exposição A quatro mãos, realizada no segundo semestre de 2010, cujo texto de apresentação informa:

Esta mostra trata da escultura como manifestação artística. Modelar o barro, esculpir a pedra e talhar a madeira são ações próprias da natureza humana. São técnicas usadas desde as mais remotas eras, tanto para a confecção de artefatos da vida cotidiana, como para dar forma à religiosidade primitiva, cujos resultados materiais, com o passar do tempo, ganharam significado artístico. São técnicas bastante antigas que ainda hoje dão suporte a grande parte da produção contemporânea.

Dentre as ações dessa exposição, destacamos a preocupação com o processo socioeducativo, tendo em vista a educação patrimonial. A proposta centra-se na vivência dos participantes através de experiências concretas que procu-

4. No primeiro semestre de 2010 o desenvolvimento de outra monografia levou as crianças ao museu, quando tiveram contato com a exposição Paisagens, de pintura, e participaram de oficina de serigrafia. ram aliar passado e presente, o que serviu para potencializar as questões abordadas em nossa oficina. O processo educativo organizado nessas bases é mais enriquecedor, pois os objetos e as evidências da cultura são investigados ao se expor a multiplicidade de significados.

O fato de já terem estado nesse museu ${ }^{4}$ fez com que as crianças se sentissem à vontade naquele espaço, do qual certamente já se tinham apropriado como extensão da escola.

\section{PASSO A PASSO: A VISITA AO MUSEU DO INGÁ}

O grupo percorreu os diferentes espaços da exposição tendo contato com diversos e estilos de esculturas.

No ambiente reservado à arte popular, estavam as carrancas esculpidas em madeira e modeladas em barro, provocando novamente efervescência e deslumbrando as crianças, que aproveitaram também para contar o que já sabiam sobre os barqueiros do Rio São Francisco.

A visita foi encerrada com um "mãos na massa" em que as crianças receberam argila para modelar suas próprias esculturas, muitas inspiradas nas carrancas.

Evidenciou-se a relevância, para a formação integral do cidadão, do fato de crianças, mesmo bem pequenas, terem contato com o patrimônio cultural através de iniciativas educacionais - sejam elas oferecidas pela escola, por museus ou outras instituições. O essencial nesse processo é estimular professor e aluno a extrapolar as fronteiras do currículo escolar e participar de atividades que envolvam conhecimento e apropriação significativa da cultura.

\section{APONTAMENTOS FINAIS}

Importante frisar que, no momento, as atividades do Programa de Extensão Casa das Mil Casas envolvem três cursos de graduação da UFF - Produção Cultural (Polo de 
Rio das Ostras), Psicologia (Polo de Rio das Ostras) e Pedagogia (Faculdade de Educação, Niterói). Para a produção cultural tornar o casarão colonial um equipamento cultural autossustentável vem servindo como estudo de caso de disciplinas do currículo, em intervenção prática que envolve os discentes, bem como campo de estágio. Bolsistas da psicologia ajudam a elaborar a proposta educacional e a formação de subjetividade que lhe é subjacente. Com os discentes de pedagogia o programa funciona como campo de pesquisa teórico-empírico para a realização de monografias e elaboração de materiais educacionais e jogos educativos a partir dos recortes temáticos do acervo que poderão ser utilizados nas oficinas.

\section{REFERÊNCIAS BIBLIOGRÁFICAS}

BENJAMIN, Walter. Experiência e pobreza. In: Obras escolhidas: magia e técnica, arte e política. São Paulo: Brasiliense, 1985.

CHAGAS, Mario; SANTOS, Myrian. A vida social e política dos objetos de um museu. Anais do Museu Histórico Nacional, v. 34, 2002.

DEWEY, John. A arte como experiência. In: Experiência e natureza; Lógica: a teoria da investigação; Arte como experiência; Vida e educação; Teoria da vida moral. São Paulo: Abril Cultural, 1980. Coleção Os Pensadores.

GEERTZ, Clifford. O saber local: novos ensaios em atropologia interpretativa. Vera Mello Joscelyne (trad.). Petrópolis: Vozes, 1997.

GONÇALVES, José Reginaldo. Antropologia dos objetos: coleções, museus e patrimônios. Rio de Janeiro: Iphan/Demu, 2007.

MACEDO, Alba Tânia Rosaura. Política de preservação cultural. In: BARRETO, Euler et al. Patrimônio cultural e educação: artigos e resultados. Goiânia: UFG, 2008.

MUSEU do Ingá. Secretaria de Cultura do Estado do Rio de Janeiro. Disponível em: www. cultura.rj.gov.br/apresentacao-espaco/museu-do-inga. Acesso em 10 mai. 2011.

PARDAL, Paulo. Carrancas do São Francisco. São Paulo: Martins Fontes, 2006.

PARDAL, Paulo. Carrancas do São Francisco. Cadernos de Folclore, n. 29, Rio de Janeiro: Funarte, 1979.

VYGOTSKY, L. S. Formação social da mente. São Paulo: Martins Fontes, 1984.

Maria Vittoria de Carvalho Pardal é doutora em psicologia social pela UFRJ, mestre em psicologia social pela Fundação Getúlio Vargas, docente da Faculdade de Educação da UFF e membro do Laboratório de Educação Patrimonial.

Adriana Russi é doutoranda em memória social pela UniRio, mestre em antropologia cultural pela PUC-SP, graduada em educação artística e docente do Curso de Produção Cultural da UFF no Polo de Rio das Ostras.

Nayara Alves Macedo é discente do Curso de Pedagogia da UFF.

Ana Luiza C. de M. Barbosa é discente do Curso de Produção Cultural da UFF e bolsista do programa de extensão. 